\title{
Effect of lactoferrin on ram sperm motility after cryopreservation
}

\author{
Jie Su ${ }^{1,2, a}$, Caiyun Wang ${ }^{1, a}$, Yongli Song ${ }^{3}$, Yanyan Yang ${ }^{4}$, and Guifang Cao ${ }^{1, *}$
}

\author{
* Corresponding Author: Guifang Cao \\ Tel: +86-13848120488, \\ E-mail: guifangcao@126.com \\ ${ }^{1}$ Inner Mongolia Key Laboratory of Basic \\ Veterinary Science, Inner Mongolia \\ Agriculture University, Hohhot 010018, China \\ ${ }^{2}$ Department of Psychosomatic Medicine, \\ Inner Mongolia Medical University, Huhhot \\ 010030, China \\ ${ }^{3}$ Research Center for Animal Genetic \\ Resources of Mongolia Plateau, Inner \\ Mongolia University, Huhhot 010021, China \\ ${ }^{4}$ Inner Mongolia Academy of Agricultured \\ and Animal Husbandry Sciences, Huhhot \\ 010000, China \\ a These authors contributed equally to this \\ work. \\ ORCID \\ Jie Su \\ https://orcid.org/0000-0002-8772-8613 \\ Caiyun Wang \\ https://orcid.org/0000-0002-2974-6151 \\ Yongli Song \\ https://orcid.org/0000-0001-9184-7853 \\ Yanyan Yang \\ https://orcid.org/0000-0002-7361-0585 \\ Guifang Cao \\ https://orcid.org/0000-0002-6177-884X
}

Submitted Dec 18, 2021; Revised Jan 19, 2022; Accepted Feb 16, 2022
Objective: The objective of this study was to analyse the differentially abundant proteins caused by freeze-thawing of ram sperm and explore candidate proteins of interest for their ability to improve ram sperm cryopreservation outcomes in vitro.

Methods: Sperm were from three mature Dorper. Fresh and frozen sperm proteins were extracted, and the differentially abundant proteins were analysed by mass spectrometry. Among these proteins, lactoferrin (LTF) was selected to be added before cryopreservation. Next, sperm samples were diluted in Tris extender, with the addition of $0,10,100,500$, and $1,000 \mu \mathrm{g} / \mathrm{mL}$ of LTF. After thawing, sperm quality was evaluated by motility, plasma membrane integrity, mitochondrial activity and reactive oxygen species (ROS).

Results: Cryopreservation significantly altered the abundance of 40 proteins; the abundance of 16 proteins was increased, while that of 24 proteins was decreased. Next, LTF was added to Tris extender applied to ram sperm. The results showed that sperm motility and plasma membrane integrity were significantly improved $(\mathrm{p}<0.05)$ by supplementation with $10 \mu \mathrm{g} / \mathrm{mL}$ LTF compared to those in the control group. There was no significant difference in mitochondrial activity between the $0 \mu \mathrm{g} / \mathrm{mL}$ group and other groups ( $>0.05)$. Supplementation of the cryoprotective extender with $10 \mu \mathrm{g} / \mathrm{mL}$ LTF led to decreased ROS levels compared with those in the control and other groups $(\mathrm{p}<0.05)$.

Conclusion: The LTF is an important protein during cryopreservation, and the addition of $10 \mu \mathrm{g} / \mathrm{mL}$ LTF to a cryoprotective extender can significantly improve the function of frozen ram sperm.

Keywords: Lactoferrin; Proteome; Ram; Sperm Cryopreservation

\section{INTRODUCTION}

The study of frozen ram sperm began in 1950 when Emmens first cooled sheep semen to $-79^{\circ} \mathrm{C}$ [1]. Jones found that the addition of a diluted solution of $1.5 \%$ dimethyl sulfoxide and 7\% glycerine increased the motility of ram sperm [2]. Furthermore, Quinn et al [3] showed that freezing changes the chemical composition and ultrastructure of ram sperm. Visser and Salamon [4] used diluted Tris to freeze ram sperm and found the lambing rate to increase to up to $40 \%$. When cryopreservation technology for ram sperm was developed in the 1990s, the conception rate still did not exceed 60\%. Pool et al [5] injected melatonin in vitro to improve semen quality after freezing. A study by Keskin et al [6] showed that $5 \%$ glycol and $1.5 \%$ glycol $+100 \mathrm{mM}$ trehalose have a strong protective effect on the ultrastructural morphology of ram sperm. In recent years, researchers have improved the cryopreservation technology of ram sperm, but sperm quality has not clearly improved after cryopreservation.

Frozen sperm are widely used in the commercial cattle breeding industry; compared to that with frozen sperm in rams, the pregnancy rate with frozen cattle sperm is higher and more stable. Differences in sperm proteomes between ram and cattle have been confirmed. Zhu et al [7] used a data-independent acquisition (DIA)-mass spectrometry (MS) proteomic 
approach to identify 238 differentially abundant proteins in ram and bull sperm. A higher abundance of sperm proteins in rams is associated with immuno-protection and sperm capacitation, while proteins that inhibit sperm capacitation are more abundant in bulls [7]. Westfalewicz et al [8] compared the proteomes of fresh, equilibrated, and cryopreserved bull semen using 2-dimensional gel electrophoresis coupled with matrix-assisted laser desorption/ionization time-of-flight MS (MALDI-TOF MS). The results revealed 16 differentially abundant proteins whose abundance was significantly changed after cryopreservation. Most sperm proteins affected by equilibration and cryopreservation are membrane bound, and the loss of those proteins may reduce natural sperm coating [8]. $\mathrm{He}$ et al [9] identified 25 differentially abundant proteins associated with cryo-damaged ram sperm using 2-dimensional gel electrophoresis coupled with MALDI-TOF MS. The results demonstrated that mitochondrial disruption and oxidative stress may play important roles in the mechanism underlying damage due to the freeze-thaw process in ram sperm [9].

In this study, we found a significant changes in lactoferrin (LTF) after cryopreservation of ram sperm. The LTF is an iron-binding glycoprotein which is present in the seminal plasma of various mammals, such as horse, porcine, bovine and human [10-13]. The LTF was identified as a sperm -binding protien, which could play a biological role in sperm maturation and for protection or regulation of sperm in corpus and cauda $[12,14]$. Earlier studies have shown that addition of LTF in sperm extender may be useful for the characteristics of sperm after freezing and thawing [15-17]. Here, MS revealed a large degree of difference after freezing in Ram spern, and identified a variety of different proteins. Interestingly, we observed that expression level of LIF was significantly decreased in sperm after freezing.

\section{MATERIALS AND METHODS}

\section{Animal care}

The Institutional Animal Care and Use Committee of Inner Mongolia Agricultural University approved the experimental protocol employed in this study.

\section{Reagents}

All reagents were purchased from Sigma-Aldrich Co. (St. Louis, MO, USA). unless indicated otherwise.

\section{Sperm collection and freeze-thaw process}

Sperm (total 6,2/ram) were collected from three mature Dorper rams with an artificial vagina. Ejaculate motility was examined using a microscope (Eclipse 80i; Nikon Corporation, Tokyo, Japan). Sperm concentration was determined with a sperm density metre (Accucell; IMV Technologies, L'Aigle, France). The ejaculates were evaluated and accepted for evaluation if the following criteria were met: individual motility: $>60 \%$ and total abnormality: $<10 \%$. Finally, three sperm samples was selected from three rams for MS. Sperm samples was diluted with Tris-A (291.7 mM Tris base, 95.1 $\mathrm{mM}$ citric acid, $70.2 \mathrm{mM}$ fructose, $20 \%$ egg yolk, $19 \mathrm{mg} / \mathrm{mL}$ tylosin, $50 \mathrm{mg} / \mathrm{mL}$ lincomycin, $100 \mathrm{mg} / \mathrm{mL}$ azithromycin, $99.01 \mathrm{mg} / \mathrm{mL}$ gentamicin, $\mathrm{pH} 6.8$ ) to $4.0 \times 10^{8} \mathrm{sperm} / \mathrm{mL}$. Diluted samples were slowly cooled to $4^{\circ} \mathrm{C}$ and allowed to equilibrate for $90 \mathrm{~min}$. After equilibration, equal amounts of Tris-B (291.7 mM Tris base, $95.1 \mathrm{mM}$ citric acid, 70.2 $\mathrm{mM}$ fructose, $20 \%$ egg yolk, $12 \%$ glycerine, $19 \mathrm{mg} / \mathrm{mL}$ tylosin, $50 \mathrm{mg} / \mathrm{mL}$ lincomycin, $100 \mathrm{mg} / \mathrm{mL}$ azithromycin, 99.01 $\mathrm{mg} / \mathrm{mL}$ gentamicin, $\mathrm{pH} 6.8$ ) were added to sperm samples at 15-min intervals. The final concentration of the frozen sperm was $2.0 \times 10^{8}$ sperm $/ \mathrm{mL}$. Samples of sperm were frozen in straws using a computer-controlled automatic freezer. After at least two days in liquid nitrogen, the samples were thawed at $37^{\circ} \mathrm{C}$ for $1 \mathrm{~min}$. Thawed sperm were transferred to centrifuge tubes and held in a water bath at $37^{\circ} \mathrm{C}$ during the entire experimental process.

\section{Extraction of sperm proteins}

The urea/thiourea method was used to extract sperm proteins [8]. The fresh and frozen sperm samples were centrifuged at $10,000 \times \mathrm{g}$ at $4^{\circ} \mathrm{C}$ for $60 \mathrm{~min}$. The sperm pellets were washed three times with phosphate-buffered saline (PBS) and centrifuged at $900 \times \mathrm{g}$ for $5 \mathrm{~min}$ at $4^{\circ} \mathrm{C}$. The sperm pellets were dissolved in lysis buffer ( $7 \mathrm{~mol} / \mathrm{L}$ urea, $2 \mathrm{~mol} / \mathrm{L}$ thiourea, $4 \%$ (w/v) 3-[(3-cholamidopropyl)-dimethylammonio]-1-propanesulfonate, $2 \%(\mathrm{w} / \mathrm{v})$ dithiothreitol, $1 \%(\mathrm{v} / \mathrm{w})$ protease inhibitor cocktail). Protein concentration was measured by the Bio-Rad Bradford protein assay using bovine serum albumin (BSA) as a standard.

\section{Mass spectrometry}

The MS and DIA experiments were performed. Raw data were acquired on a Q Exactive HF mass spectrometer coupled with an Easy nanoLC 1000 chromatograph (Thermo Scientific, Waltham, MA, USA). Briefly, $3 \mu$ g of peptides was loaded onto a home-packed column $(150 \mathrm{~m} \times 15 \mathrm{~cm}$, ReproSil-Pur C18-AQ, $1.9 \mu \mathrm{m}$, Dr. Maisch GmbH, Ammerbuch, Germany) with an integrated spray tip. The peptides were separated with a 180 -min gradient (from $5 \%$ to $13 \%$ B in 13 $\mathrm{min}$, from $13 \%$ to $30 \% \mathrm{~B}$ in $145 \mathrm{~min}$, from $30 \%$ to $45 \% \mathrm{~B}$ in $15 \mathrm{~min}$, from $45 \%$ to $95 \% \mathrm{~B}$ in $1 \mathrm{~min}$, and held at $95 \%$ B for $6 \mathrm{~min}$; buffer A was $0.1 \%(\mathrm{v} / \mathrm{v})$ formic acid in water, and buffer B was $0.1 \%(\mathrm{v} / \mathrm{v})$ formic acid in $\mathrm{ACN}$ ) at a flow rate of $600 \mathrm{~nL} / \mathrm{min}$. The column was coupled to a column heater (Allwegene Technology Co., Ltd. Beijing, China), and the temperature was set to $60^{\circ} \mathrm{C}$. The sample raw data obtained by DIA were imported for quantitation, all detected peaks were reintegrated by using the mProphet peak-scoring model 
(each dataset and iteration were trained independently), and the q-value annotation was added to each peak. Then, the protein quantitation results were exported with MSstats [18] for further bioinformatics analysis.

\section{Western blotting}

Differentially abundant proteins were screened, and we selected the LTF protein for western blot analysis to validate its abundance in fresh and frozen-thawed ram sperm.

Extracted sperm proteins were separated by sodium dodecyl sulfate-polyacrylamide gel electrophoresis using a $12 \%$ gel. After transfer onto a PVDF membrane by electroblotting, the membrane was incubated overnight with anti-LTF polyclonal antibody as the primary antibody at a 1:1,000 dilution at $4^{\circ} \mathrm{C}$, washed in TBS-T, and incubated with goat antirabbit IgG H\&L/HRP antibody (immunoglobulin $\mathrm{G}$ [IgG]; horseradish peroxidase [HRP]) (BS-0295G-HRP; Bioss, Beijing, China) at a 1:2,000 dilution for $2 \mathrm{~h}$. After rinsing the membranes in TBST again, the protein bands were visualized using the Odyssey infrared imaging system (LI-COR Biosciences, Lincoln, NE, USA). The films were scanned, and all the data were entered into SPSS statistical software (SPSS, Inc., Chicago, IL, USA) and analysed using a two-sample t test.

\section{Immunofluorescence}

Smears of the final suspension of sperm in diluent were airdried on microscope slides at room temperature and fixed in methanol, after which the slides were washed three times in PBS for $10 \mathrm{~min}$ and blocked for $30 \mathrm{~min}$ at room temperature in $5 \%$ BSA. Sperm were incubated overnight at $4^{\circ} \mathrm{C}$ with anti-LTF (BS-5810R; Bioss, China) (1:400). For the negative control, PBS was used instead of primary antibody. Next, sperm were incubated with Alexa Fluor 555-conjugated goat anti-rabbit IgG H\&L (1:400) (BS-0295G-AF555; Bioss, China) for $1 \mathrm{~h}$ at $37^{\circ} \mathrm{C}$. Finally, sperm were incubated in the dark at $37^{\circ} \mathrm{C}$ for $10 \mathrm{~min}$ for staining with DAPI (4',6-diamidino2 -phenylindole). Images were obtained using a confocal laser microscope (LSM; Zeiss, Oberkochen, Germany); red fluorescence on the images indicated positivity.

\section{Lactoferrin treatment of sperm}

Each ejaculate was diluted with Tris extender containing LTF $(10,100,500$, and $1,000 \mu \mathrm{g} / \mathrm{mL}$ ) or without LTF (control).

\section{Assessment of semen quality parameters}

Sperm motility: Samples were adjusted to a concentration of $5.0 \times 10^{6}$ sperm $/ \mathrm{mL}$, placed on a slide, covered with a coverslip and assessed by microscopic observation on a warm $\left(38^{\circ} \mathrm{C}\right)$ stage. Motility is expressed as the percentage of motile sperm with moderate to vigorous linear progressive movement in all microscopic fields examined. At least 200 sperm were tracked and analysed at $38^{\circ} \mathrm{C}$ to assess the proportion of motile sperm.

Sperm membrane integrity: Sperm membrane integrity was assessed using a combination of 6-carboxyfluorescein diacetate (6-CFDA) and propidium iodide (PI) as previously described [19]. Take $50 \mu \mathrm{L}$ of sperm and dilute with $150 \mu \mathrm{L}$ of Tris without glycerol or egg yolk containing $5 \mu \mathrm{L}$ of 6-CFDA $(0.46 \mathrm{mg} / \mathrm{mL})$ and $20 \mu \mathrm{L}$ PI $(0.5 \mathrm{mg} / \mathrm{mL})$ and incubated in the dark at $37^{\circ} \mathrm{C}$ for $10 \mathrm{~min}$, and $0.5 \%$ glutaraldehyde was then added for fixation. Sperm membrane integrity was observed with an Olympus FluoView (ver. 2.1a; Olympus, Tokyo, Japan). At least 200 sperm per slide were examined and scored for dye deposition. Sperm displaying green-red or red fluorescence were considered to have membrane damage, whereas those displaying green fluorescence were considered to have an intact membrane.

Sperm acrosome integrity: Sperm acrosome integrity was assessed using fluorescein isothiocyanate conjugated to peanut agglutinin (FITC-PNA) and by PI staining as described by Bucak et al [20]. Take $50 \mu \mathrm{L}$ of sperm and mix with $10 \mu \mathrm{L}$ of FITC-PNA $(0.12 \mathrm{mg} / \mathrm{mL})$ and $2.5 \mu \mathrm{L}$ of PI. The samples were incubated at $37^{\circ} \mathrm{C}$ for $10 \mathrm{~min}$ in the dark, and $0.5 \%$ glutaraldehyde was then added for fixation. Sperm acrosome integrity was observed with an Olympus FluoView (ver. 2.1a; Olympus, Japan). At least 200 sperm per slide were examined to record the percentage of fluorescent, acrosome-intact sperm. Sperm displaying bright green or patchy green fluorescence were considered to have a non-intact or damaged acrosome, whereas cells that did not display green fluorescence in the acrosome cap were regarded as having an intact acrosome.

Sperm mitochondrial activity: Sperm mitochondrial activity was assessed with JC-1 with a protocol from Gravance et al [21]. Take $50 \mu \mathrm{L}$ of sperm sample and dilute with $150 \mu \mathrm{L}$ of Tris without glycerol or egg yolk containing $5 \mu \mathrm{L}$ of the lipophilic cationic fluorochrome JC-1 (0.15 mM in DMSO) and incubated at $37^{\circ} \mathrm{C}$ for $10 \mathrm{~min}$ in the dark, and $0.5 \%$ glutaraldehyde was then added for fixation. At least 200 sperm per slide were examined to record the percentage of fluorescent sperm. Sperm were classified as having high mitochondrial membrane activity when the midpiece emitted yellow/orange fluorescence and low mitochondrial membrane activity when green fluorescence was emitted.

Intracellular reactive oxygen species measurements: Sperm intracellular reactive oxygen species (ROS) were assessed using 2'7'-dichlorofluorescin diacetate (DCFH-DA). Take $50 \mu \mathrm{L}$ sperm samples and dilute with $150 \mu \mathrm{L}$ of Tris without glycerol or egg yolk containing $5 \mu \mathrm{M}$ DCFH-DA and incubated at $37^{\circ} \mathrm{C}$ for $30 \mathrm{~min}$ in the dark, and $0.5 \%$ glutaraldehyde was then added for fixation. DCFH oxidation by ROS from plasma generated DCF, and DCF fluorescence intensity was read (with a SpectraMax reader) at an excitation wavelength of $485 \mathrm{~nm}$ and an emission wavelength of 
$530 \mathrm{~nm}$

\section{Statistical analysis}

Values obtained upon assessment of the 5 sperm quality parameters (motility, membrane integrity, mitochondrial activity, Intracellular ROS measurements) are expressed as mean \pm SEM. The statistical software SPSS ver. 15.0 for Windows (SPSS Inc., USA) was used for the analysis. A probability level of $<0.05$ was considered to indicate significance.

Proteins with a false discovery rate below $1 \%$ were exported for statistical analysis. A t-test ( $\alpha$ of 0.05 ) was used to compare fresh versus frozen sperm protein samples. High fold change of $>1.5$ or $<0.5$ was applied as an additional cut-off to ensure statistical significance, and $\mathrm{p}$ values were corrected for multiple testing by controlling for a $1 \%$ false discovery rate during analysis using the Benjamini-Hochberg method.

\section{RESULTS}

Significantly differentially abundant proteins after the cryopreservation of ram sperm

Sperm were screened with an abundance ratio $\geq 1.5$ or $\leq 0.5$ and a $\mathrm{p} \leq 0.05$ as screening conditions, which identified 40 differentially abundant proteins when fresh sperm and frozen sperm were compared; among these proteins, 16 were upregulated in frozen sperm, and 24 were downregulated (Table 1).

Gene ontology (GO) annotation of enriched cellular components revealed that most proteins whose abundance was increased after cryopreservation are present in the cytoskeleton, nucleus, mitochondrion, or cytoplasm. The GO annotation of molecular function revealed that the most prevalent terms represented were catalytic activity, structural molecular activity and nucleotide binding. The differentially abundant proteins whose abundance decreased after cryopreservation were located in the extracellular region or secreted or found in the cytosol, nucleus. The GO annotation of molecular function revealed that the most prevalent represented terms were catalytic activity, ATP binding and phosphatase activity (Figure 1).

\section{Western blotting}

Among the differentially abundant proteins, LTF was selected to validate the proteomics results. The changes in protein levels determined by western blot analysis (shown in Figure 2) were generally consistent with the variations recorded in the LC-MS/MS analysis. The LTF level was decreased in ram sperm after freezing.

\section{Immunofluorescence}

Assessment of the LTF immunofluorescent signal showed that LTF (Figure 3) was clearly visible but minimally abun- dant in the semen flagellum. The abundance of LTF was decreased in frozen semen compared to fresh sperm.

\section{Lactoferrin treatment of frozen ram sperm}

The effects of LTF supplementation (L9705; Sigma, USA) of the cryoprotective extender on ram sperm qualities are shown in Table 2 . The motility and plasma membrane integrity were significantly improved $(\mathrm{p}<0.05)$ by supplementation with $10 \mu \mathrm{g} / \mathrm{mL}$ LTF. There was no significant difference in mitochondrial activity between the control group and the other groups. Supplementation of the cryoprotective extender with $10 \mu \mathrm{g} / \mathrm{mL}$ LTF led to decreased ROS levels compared with those in the control and other groups.

\section{DISCUSSION}

In the present study, MALDI-TOF/TOF MS was used to determine changes in ram sperm proteins after cryopreservation. A total of 40 proteins underwent significant changes in abundance. Twenty-four sperm proteins decreased in abundance during cryopreservation, and 16 sperm proteins increased in abundance. The proteomes of ram sperm before and after freezing have been described using different proteomic technologies. Pini et al [22] reported that cryopreservation significantly altered the abundance of 51 proteins, among which the levels of 27 proteins increased, while those of 24 proteins decreased in frozen-thawed ram sperm. In another study, He et al [9] identified 21 proteins whose abundance differed between fresh and frozen-thawed ram sperm by two-dimensional electrophoresis. The abundance of 13 sperm proteins decreased, while that of 8 proteins increased during cryopreservation. Cryopreservation of sperm involves many separate processes, each of which may contribute to alteration of the sperm proteome. Few of the proteins that we identified as significantly altered in abundance following cryopreservation have been identified in other studies. This may be the result of differences in the cryoprotective extender or the methods used for quantitation of the differences. Most of the up-regulated proteins were involved in an apoptosis-stress response and several biological processes increased during sperm capacitation or cryo-capacitation; meanwhile, most of the down-regulated proteins were implicated in immunity and other relevant sperm functions. The cause of the increase in protein abundance upon cryopreservation is not known.

The loss of proteins itself may lead to sublethal sperm damage and lower sperm function after thawing. In our study, 24 sperm proteins decreased in abundance during cryopreservation. Seven of these proteins, DEFB133, LGALS3BP, LTF, BPIFA1, PGLYRP1, GLOD4, and GLB1, are located in the extracellular region or are secreted. Among these proteins, LTF was identified as a sperm-binding protein that may play 
Table 1. Proteins differentially abundant between fresh ram sperm and frozen sperm

\begin{tabular}{|c|c|c|c|c|c|}
\hline $\begin{array}{l}\text { Uniprot access } \\
\text { number }\end{array}$ & Protein name & Mean fresh & Mean frozen & p-value & $\begin{array}{l}\text { Fold change } \\
\text { (Frozen/fresh) }\end{array}$ \\
\hline K4P1S5 & Peptidyl-prolyl cis-trans isomerase & $3,707,874,819$ & $5,599,710,656$ & 0.01341 & 1.51022106 \\
\hline W5PSZ6 & Testis anion transporter 1 & $1,767,609,471$ & $2,699,264,635$ & 0.02516 & 1.52707070 \\
\hline W5PUU4 & SPEM family member 2 & $1,274,951,062$ & $2,023,261,858$ & 0.03450 & 1.58693295 \\
\hline W5PUD8 & Mitochondrial amidoxime reducing component 2 & $178,184,674$ & $284,574,082$ & 0.04709 & 1.59707384 \\
\hline A0A0A7AK60 & Cytochrome b & $764,492,041$ & $1,228,232,142$ & 0.00063 & 1.60659899 \\
\hline W5Q665 & Keratin 13 & $13,295,282,486$ & $23,506,798,852$ & 0.00086 & 1.76805561 \\
\hline W5Q611 & Keratin 1 & $2,060,133,276$ & $4,077,639,334$ & 0.03506 & 1.97930851 \\
\hline W5QEU2 & Poly [ADP-ribose] polymerase & $1,248,508,039$ & $3,097,205,302$ & 0.00031 & 2.48072515 \\
\hline W5Q160 & Keratin 10 & $1,514,687,200$ & $4,218,898,678$ & 0.00045 & 2.78532668 \\
\hline W5QFN4 & Succinyl-CoA:3-ketoacid-coenzyme A transferase & $732,737,023$ & $2,376,841,286$ & 0.00913 & 3.24378489 \\
\hline W5PVP5 & Adenine phosphoribosyltransferase & $2,285,213,650$ & $91,102,607$ & 0.04831 & 0.00880968 \\
\hline W5PST9 & Beta-defensin & $91,238,445,779$ & $5,078,394,089$ & 0.00015 & 0.05407310 \\
\hline A4GZY3 & Seminal vesicle protein & $82,867,236,507$ & $5,838,425,974$ & 0.01171 & 0.07699096 \\
\hline W5PMZ6 & Alpha-mannosidase & $14,644,733,570$ & $1,934,251,271$ & 0.00096 & 0.13207828 \\
\hline A0A075W0S2 & BPI fold containing family A member 1 & $14,644,733,570$ & $1,131,967,594$ & 0.00257 & 0.16079215 \\
\hline W5QBA7 & 3-phosphoinositide dependent protein kinase 1 & $14,869,965,871$ & $1,372,953,284$ & 0.02388 & 0.20384992 \\
\hline W5NZ70 & Galectin 3 binding protein & $380,648,426$ & $81,347,833$ & 0.00735 & 0.21370857 \\
\hline W5P3C6 & Beta-hexosaminidase & $15,535,334,719$ & $3,423,356,047$ & 0.00175 & 0.22035933 \\
\hline W5PP77 & Glyoxalase domain containing 4 & $359,971,895$ & $50,193,314$ & 0.03229 & 0.24004450 \\
\hline W5P7T9 & KIAA1468 & $380,648,426$ & $29,867,839$ & 0.01483 & 0.26614296 \\
\hline W5NT19 & Sperm associated antigen 1 & $10,568,960,720$ & $1,843,614,094$ & 0.03940 & 0.44507809 \\
\hline W5PYU5 & Spalt like transcription factor 4 & $34,194,681$ & $6,912,804$ & 0.00517 & 0.45010647 \\
\hline B2LYK4 & RAS oncogene family-like 4 & $40,454,561$ & $18,208,859$ & 0.00517 & 0.45010647 \\
\hline W5PCB3 & Small VCP interacting protein & $633,518,665$ & $305,761,430$ & 0.01191 & 0.47078067 \\
\hline W5P1Q0 & AP complex subunit beta & $622,622,997$ & $575,674,784$ & 0.03461 & 0.47234615 \\
\hline W5PSZ8 & Triokinase and FMN cyclase & $23,864,858,955$ & $12,281,003,018$ & 0.00675 & 0.47652161 \\
\hline C5IJA4 & ATXN3 & $26,677,404,693$ & $12,712,359,829$ & 0.00675 & 0.47652161 \\
\hline
\end{tabular}

1) Differentially expressed (>1.5-fold or $\leq 0.5)$ proteins of sperm after cryopreservation.

a role in the protection and regulation of sperm activity [10, 12]. Kobayashi et al [15] reported that LTF may be useful for the modulation of bovine sperm viability, motility, capacitation state, and cryopreservation in vitro. Martins reported that LTF supplementation was beneficial in protecting stallion sperm during freezing, as it increased the percentage of sperm with a functional membrane and decreased lipid oxidant agents [17]. It is difficult to state the effect of the other proteins differentially expressed genes on sperm after freezing, because we could not find the related functional annotations in GenBank and related research. Therefore, we chose LTF for further research.

Cryopreservation has been reported to induce damage to sperm and the overproduction of ROS. Excessive generation of ROS during cryopreservation leads to major changes in proteins, lipids and carbohydrates in the sperm membrane, resulting in the loss of sperm motility [23]. $\mathrm{Fe}^{3+}$ is present at a very low concentration in almost all solutions and can catalyse the formation of hydroxyl radicals from $\mathrm{O}_{2}$ and $\mathrm{H}_{2} \mathrm{O}_{2}$. The presence of $\mathrm{Fe}^{3+}$, a catalytic transition metal, hastens the 
(A1)

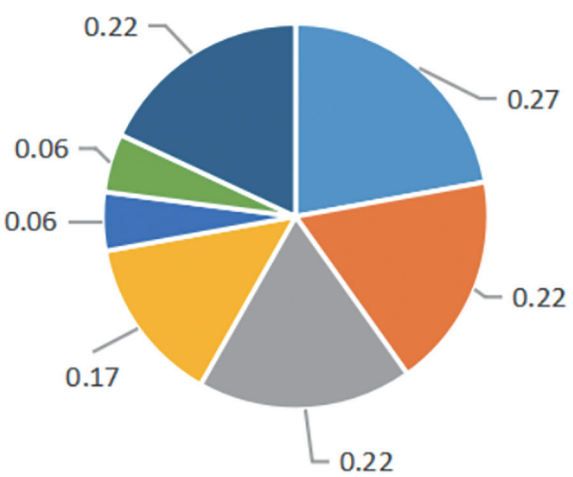
- Cytoskeleton
- Mitochondrion
- Cytosol

- Mitochondrion

(B1)

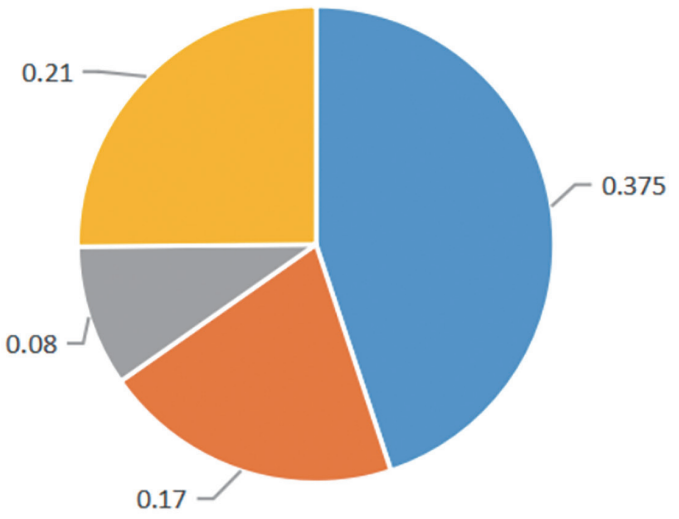

a catalytic activity $\quad$ ATP binding $\quad$ phosphatase activity $\quad$ others
(A2)

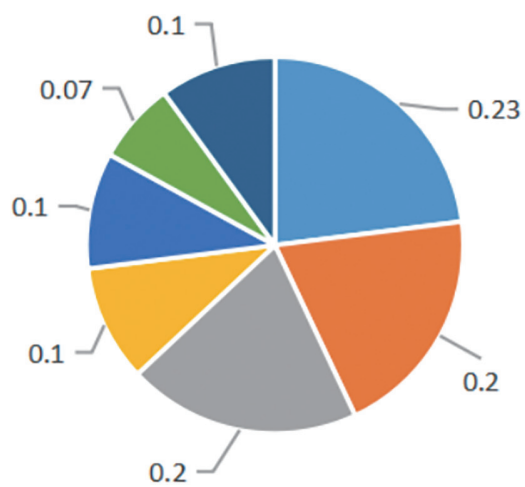

- Extracellular region or secreted nucleus

- Cytosol a Cytoplasm

- Mitochondrion a Cytoskeleton

others

(B2)

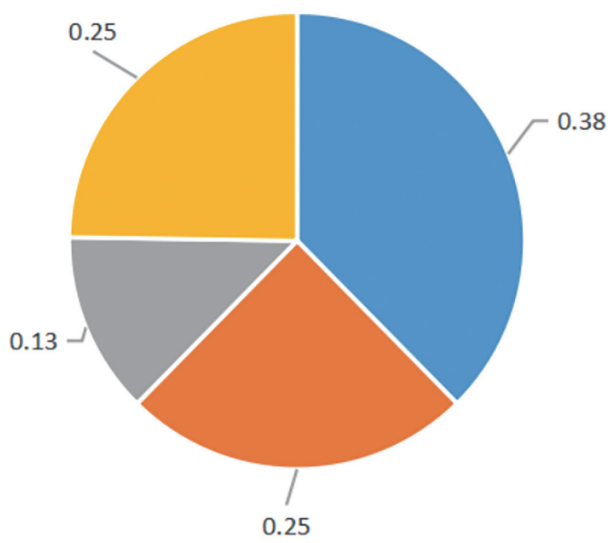

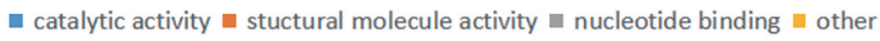

Figure 1. Classification of the identified proteins in fresh and cryopreserved ram sperm. According to their (A) subcelluar location, (B), molecular function. (A1), (B1) Proteins were upregulated in frozen sperm; (A2), (B2) Proteins were downregulated in frozen sperm.

(A)

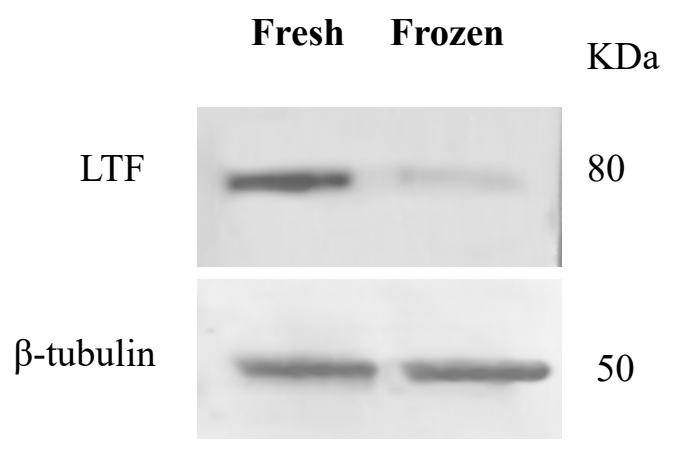

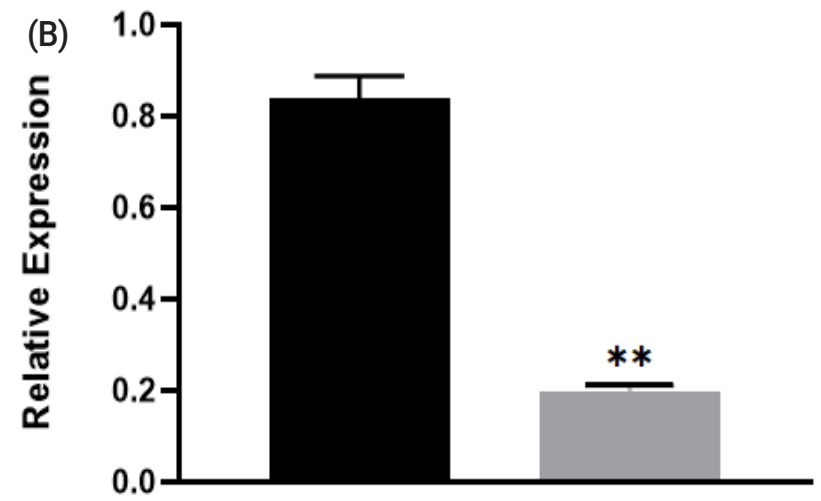

Fresh
Frozen

Figure 2. Expression of lactoferrin (LTF) before and after cryopreservation. Western blotting analysis of protein expression in fresh and freezethawed ram sperm (A). Relative expression levels of LTF in fresh and frozen-thawed sperm (B). Values represent the average \pm standard error of the mean from three gels per group. Asterisks indicate a statistically significant difference from the fresh group: ${ }^{\star \star} p<0.001$ from one-way analysis of variance with Duncan's post hoc analysis. 
DAPI

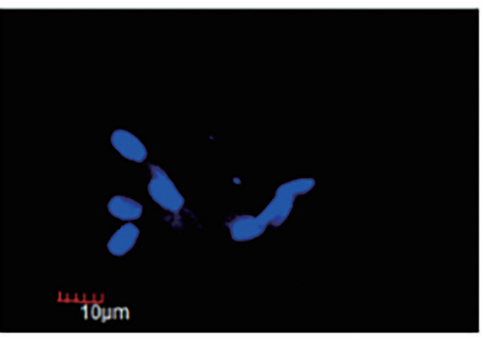

Fresh

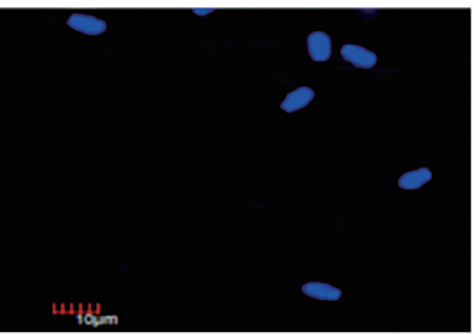

Frozen

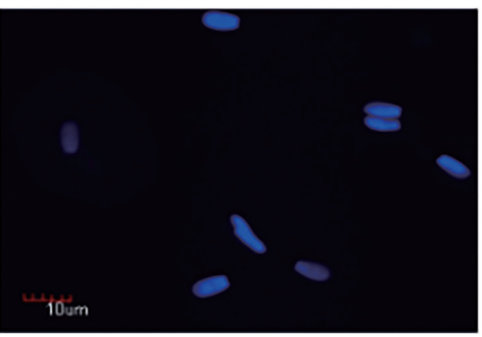

LTF
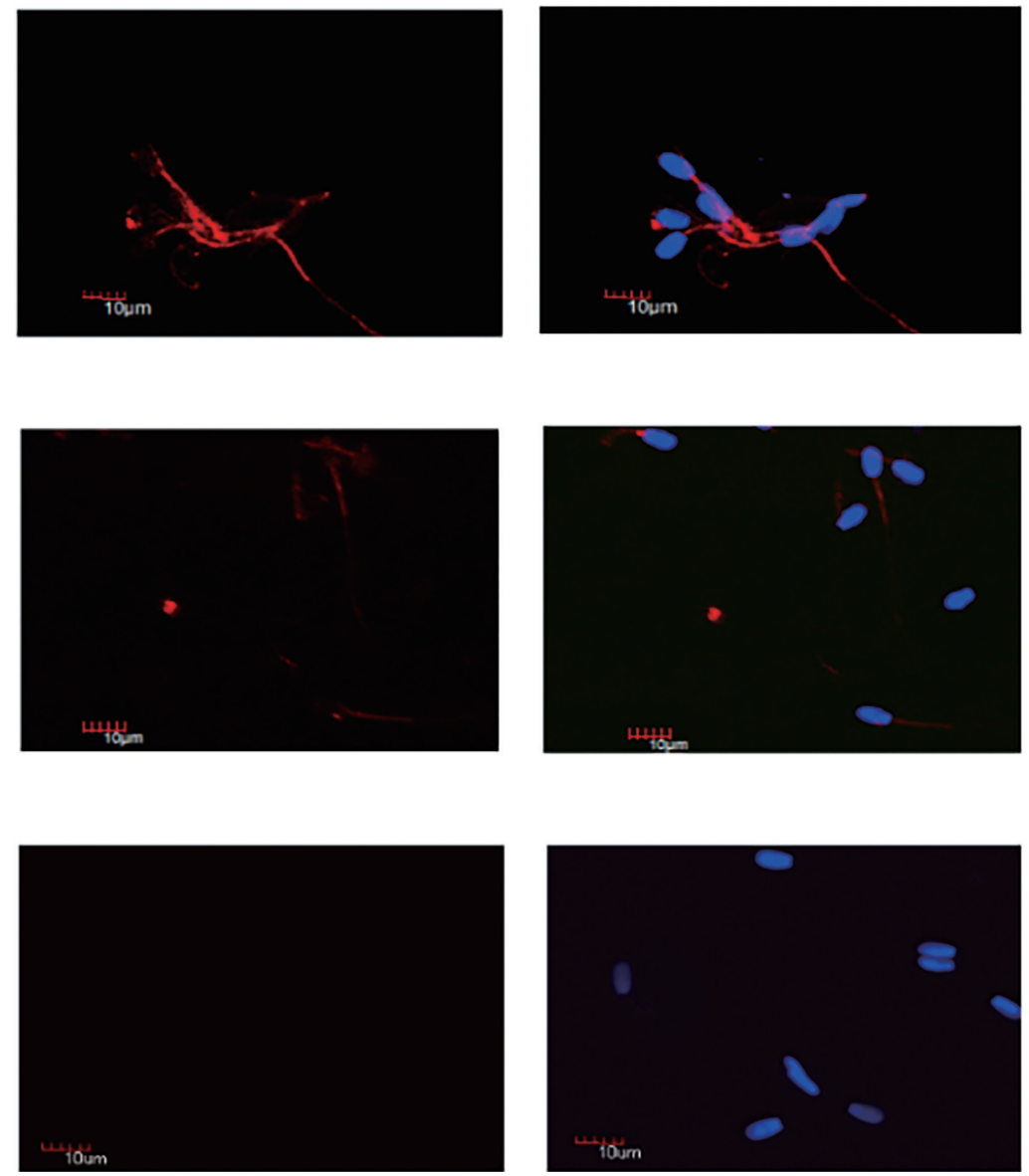

Figure 3. Immunofluorescence localization analysis of lactoferrin (LTF) in ram sperm. Immunofluorescence localization analysis of LTF in ram sperm. Staining was performed at 400xmagnification. DAPI (4',6-diamidino-2-phenylindole) (blue) and LTF (red).

Table 2. Effects of lactoferrin on the motility, mebrane integrity, mitochondrial activity and ROS content in ram sperm berore and after cryopreservation

\begin{tabular}{lccccc}
\hline Items (\%) & $\mathbf{0} \boldsymbol{\mu g} / \mathbf{m L}$ & $\mathbf{1 0} \boldsymbol{\mu g} / \mathbf{m L}$ & $\mathbf{1 0 0} \boldsymbol{\mu g} / \mathbf{m L}$ & $\mathbf{5 0 0} \boldsymbol{\mu g} / \mathbf{m L}$ & $\mathbf{1 , 0 0 0} \boldsymbol{\mu g} / \mathbf{m L}$ \\
\hline Motility & $26.7 \pm 6.07^{\mathrm{a}}$ & $41 \pm 3.2^{\mathrm{b}}$ & $32.7 \pm 3.9^{\mathrm{ab}}$ & $30.2 \pm 3.8^{\mathrm{ab}}$ & $27.0 \pm 6.0^{\mathrm{ab}}$ \\
Membrane integrity & $12.4 \pm 0.3^{\mathrm{a}}$ & $17.9 \pm 0.1^{\mathrm{b}}$ & $12.1 \pm 0.7^{\mathrm{a}}$ & $11.7 \pm 0.4^{\mathrm{a}}$ & $11.0 \pm 0.2^{\mathrm{a}}$ \\
Mitochondrial activity & $24.2 \pm 6.1^{\mathrm{a}}$ & $32.9 \pm 6.0^{\mathrm{a}}$ & $24.7 \pm 3.2^{\mathrm{a}}$ & $25.5 \pm 4.8^{\mathrm{a}}$ & $21.5 \pm 3.5^{\mathrm{a}}$ \\
ROS & $81.5 \pm 5.5^{\mathrm{a}}$ & $61.5 \pm 1.5^{\mathrm{b}}$ & $68.5 \pm 1.5^{\mathrm{a}}$ & $74.2 \pm 3.2^{\mathrm{a}}$ & $78.5 \pm 5.5^{\mathrm{a}}$ \\
\hline
\end{tabular}

Values represent averages \pm standard error of the mean $(n=3)$.

ROS, reactive oxygen species.

a,b Different superscript letters in the same row indicate significant differences $(p<0.05)$.

initiation of lipid peroxidation [24]. LTF can remove $\mathrm{Fe}^{3+}$ from the extracellular space and prevent its catalytic effects. The results in the present study revealed positive and negative effects of LTF at different concentrations. Supplementation of the cryoprotective extender with LTF at a concentration of $10 \mu \mathrm{g} / \mathrm{mL}$ resulted in a significant increase in sperm motility and plasma membrane integrity $(\mathrm{p}<0.05)$, while ROS levels were decreased compared with those in the control and other groups.

\section{CONCLUSION}

The LTF decreased in abundance during cryopreservation. In vitro experiment suggested that the addition of $10 \mu \mathrm{g} / \mathrm{mL}$ LTF to a Tris extender can significantly improve the function of frozen ram sperm. LTF play an important role during cryo- 
preservation of ram sperm and can significantly improve the function of frozen ram sperm.

\section{CONFLICT OF INTEREST}

We certify that there is no conflict of interest with any financial organization regarding the material discussed in the manuscript.

\section{FUNDING}

This study was supported by Inner Mongolia Scientific and Technological Achievement Transformation guide project: Industrialization of sex control propagation technology of dairy goats and sheep (NO.2020CG0078).

\section{REFERENCE}

1. Larsson K, Einarsson S. Influence of boars on the relationship between fertility and post thawing sperm quality of deep frozen boar spermatozoa. Acta Vet Scand 1976;17:74-82. https://doi.org/10.1186/BF03547944

2. Jones RC. The use of dimethyl sulphoxide, glycerol, and reconstituted skim milk for the preservation of ram spermatozoa. II. The influence of diluent composition and processing time during freezing to minus 79 degrees $\mathrm{C}$ with dimethyl sulphoxide or glycerol or both compounds. Aust J Biol Sci 1965; 18:887-900. https://doi.org/10.1071/BI9650887

3. Quinn PJ, White IG, Cleland KW. Chemical and ultrastructural changes in ram spermatozoa after washing, cold shock and freezing. J Reprod Fertil 1969;18:209-20. https:// doi.org/10.1530/jrf.0.0180209

4. Visser D, Salamon S. Fertility of ram spermatozoa frozen in a tris-based diluent. Aust J Biol Sci 1973;26:513-5. https:// doi.org/10.1071/BI9730513

5. Pool KR, Rickard JP, Tumeth E, Graaf SD. Treatment of rams with melatonin implants in the non-breeding season improves post-thaw sperm progressive motility and DNA integrity. Anim Reprod Sci 2020;221:106579. https://doi. org/10.1016/j.anireprosci.2020.106579

6. Keskin N, Erdogan C, Bucak MN, Ozturk AE, Dursun S. Cryopreservation effects on ram sperm ultrastructure. Biopreserv Biobank 2020;18:441-8. https://doi.org/10.1089/bio.2020. 0056

7. Zhu W, Cheng X, Ren C, et al. Proteomic characterization and comparison of ram (Ovis aries) and buck (Capra hircus) spermatozoa proteome using a data independent acquisition mass spectometry (DIA-MS) approach. Plos One 2020;15: e0228656. https://doi.org/10.1371/journal.pone.0228656

8. Westfalewicz B, Dietrich MA, Ciereszko A. Impact of cryopreservation on bull (Bos taurus) semen proteome. J Anim Sci 2015;93:5240. https://doi.org/10.2527/jas.2015-9237
9. He Y, Wang K, Zhao X, Zhang Y, Ma Y. Differential proteome association study of freeze-thaw damage in ram sperm. Cryobiology 2016;72:60-8. https://doi.org/10.1016/j.cryobiol. 2015.11.003

10. Inagaki M, Kikuchi M, Orino K, Ohnami Y, Watanabe K. Purification and quantification of lactoferrin in equine seminal plasma. J Vet Med Sci 2002;64:75-7. https://doi.org/10.1292/ jvms.64.75

11. Pearl CA, Roser JF. Expression of lactoferrin in the boar epididymis: effects of reduced estrogen. Domest Anim Endocrinol 2008;34:153-9. https://doi.org/10.1016/j.domaniend.2007. 01.001

12. Pearl CA, Roser JF. Lactoferrin expression and secretion in the stallion epididymis. Reprod Biol 2014;14:148-54. https:// doi.org/10.1016/j.repbio.2013.10.005

13. Zumoffen CM, Massa E, Caille AM, Munuce MJ, Ghersevich SA. Effects of lactoferrin, a protein present in the female reproductive tract, on parameters of human sperm capacitation and gamete interaction. Andrology 2015;3:1068-75. https:// doi.org/10.1111/andr.12093

14. Jin YZ, Bannai S, Dacheux F, Dacheux JL, Okamura N. Direct evidence for the secretion of lactoferrin and its binding to sperm in the porcine epididymis. Mol Reprod Dev 1997;47: 490-6. https://doi.org/10.1002/(SICI)1098-2795(199708)47: 4<490::AID-MRD16>3.0.CO;2-\%23

15. Kobayashi J, Suda Y, Takada N, et al. 14 motility and fertility of bull spermatozoa frozen in egg yolk extender supplement with lactoferrin. Reprod Fertil Dev 2006;19:125-6. https://doi. org/10.1071/RDv19n1Ab14

16. Kobayashi J, Sasaki A, Watanabe A, et al. Effects of exogenous lactoferrin on characteristics and functions of bovine epididymal, ejaculated and frozen-thawed sperm. Anim Sci J 2021; 92:e13538. https://doi.org/10.1111/asj.13538

17. Martins HS, Da Silva GC, Cortes SF, et al. Lactoferrin increases sperm membrane functionality of frozen equine semen. Reprod Domest Anim 2018;53:617-23. https://doi.org/10. 1111/rda.13148

18. Choi M, Chang CY, Clough T, et al. MSstats: an R package for statistical analysis of quantitative mass spectrometry-based proteomic experiments. Bioinformatics 2014;30:2524-6. https:// doi.org/10.1093/bioinformatics/btu305

19. Silva ECB, Cajueiro JFP, Silva SV, Soares PC, Guerra MMP. Effect of antioxidants resveratrol and quercetin on in vitro evaluation of frozen ram sperm. Theriogenology 2012;77: 1722-6. https://doi.org/10.1016/j.theriogenology.2011.11.023

20. Bucak MN, Ataman MB, Bapnar N, et al. Lycopene and resveratrol improve post-thaw bull sperm parameters: sperm motility, mitochondrial activity and DNA integrity. Andrologia 2015;47:545-52. https://doi.org/10.1111/and.12301

21. Gravance CG, Garner DL, Baumber J, Ball BA. Assessment of equine sperm mitochondrial function using JC-1. Theriogenology 2000;53:1691-703. https://doi.org/10.1016/S0093- 
691X(00)00308-3

22. Pini T, Rickard JP, Leahy T, Crossett B, Druart X, de Graaf SP. Cryopreservation and egg yolk medium alter the proteome of ram spermatozoa. J Proteomics 2018;181:73-82. https:// doi.org/10.1016/j.jprot.2018.04.001

23. Casas I, Sancho S, Briz M, et al. Freezability prediction of boar ejaculates assessed by functional sperm parameters and sperm proteins. Theriogenology 2009;72:930-48. https:// doi.org/10.1016/j.theriogenology.2009.07.001

24. Lamirande ED, Jiang H, Zini A, Kodama H, Gagnon C. Reactive oxygen species and sperm physiology. Rev Reprod 1997; 2:48-54. https://doi.org/10.1530/ror.0.0020048 